\title{
Effect of Ultrasound on L-leucine Production by Corynebacterium Glutamicum in Fed-batch Culture
}

\section{Yufu Zhang ( $\nabla$ yfz362@sina.com )}

Tianjin university of science and technology https://orcid.org/0000-0003-0648-2058

\section{Zhichao Chen}

Tianjin University of Science and Technology College of Biotechnology

\section{Pengjie Sun}

Tianjin University of Science and Technology College of Biotechnology

\section{Qingyang Xu}

Tianjin University of Science and Technology College of Biotechnology

\section{Ning Chen}

Tianjin University of Science and Technology College of Biotechnology

\section{Research}

Keywords: ultrasound, L-leucine, fermentation, Corynebacterium glutamicum, response surface methodology, fed-batch culture

Posted Date: December 22nd, 2020

DOl: https://doi.org/10.21203/rs.3.rs-131810/v1

License: (c) (i) This work is licensed under a Creative Commons Attribution 4.0 International License.

Read Full License 
Effect of ultrasound on L-leucine production by Corynebacterium glutamicum in fed-batch culture

Yufu Zhang ${ }^{1,2}$, Zhichao Chen ${ }^{1,2}$, Pengjie Sun ${ }^{1,2}$, Qingyang $\mathrm{Xu}^{1,2 *}$ and Ning Chen ${ }^{1,2 *}$

1. National and Local United Engineering Lab of Metabolic Control Fermentation Technology, Tianjin University of Science \& Technology, Tianjin 300457, PR China

2. College of Biotechnology, Tianjin University of Science \& Technology, Tianjin 300457, PR China

*Corresponding author:

Dr. Qingyang Xu, College of Biotechnology, Tianjin University of Science \& Technology, No. 29, 13 Main Street, Tianjin Economic and Technological Development Area, Tianjin 300457, PR China; Tel: 86-22-60601251; Fax: +86-022-60601251; Email: xuqingyang@tust.edu.cn

Dr. Ning Chen, College of Biotechnology, Tianjin University of Science \& Technology, No. 29, 13 Main Street, Tianjin Economic and Technological Development Area, Tianjin 300457, PR China; Tel: 86-22-60601251; Fax: +86-022-60601251; E-mail: chenning608@126.com

E-mail addresses of other authors:

Y. Zhang: yfz362@sina.com;

Z.Chen:czc101x@163.com;

P Sun: 1559134227@qq.com; 


\section{Abstract}

2 Background: Various process intensifications are proposed to improve process 3 efficiency, quality, and safety of fermented products. With the market significantly 4 growing, the production process of L-leucine needs significant improvements to 5 increased productivity and yield. Ultrasound, a process intensification, is an emerging and fast-growing technology due to its wide range of applications in food science and 7 fermentation industry.

8 Results: By optimizing the time points and parameters of ultrasound, the biomass of Corynebacterium glutamicum $\mathrm{CP}$ was significantly improved. The response surface methodology was adopted to create prediction profiler model and optimize sonication conditions. C. glutamicum CP fermentation at conditions of ultrasonic power of $94 \mathrm{~W} / \mathrm{L}$, frequency of $25 \mathrm{kHz}$, interval of $31 \mathrm{~min}$, and duration of $37 \mathrm{~s}$ produced $52.89 \mathrm{~g} / \mathrm{L}$ of Lleucine in $44 \mathrm{~h}$, increased by $21.6 \%$ compared with the control. The production performance of L-leucine was also improved under ultrasonic treatment. Moreover, the cell morphology of C. glutamicum CP were more irregular, elongated, and swollen cells under the ultrasonic condition. The cell permeability of $C$. glutamicum $\mathrm{CP}$ and the activity of key enzymes with ultrasonic treatment were significantly higher than the control.

19 Conclusions: We successfully obtain the optimum ultrasonic conditions to produce Lleucine in fed-batch culture. The results indicate that ultrasonication is an efficient intensification process for enhancing fermentation to produce L-leucine from $C$. glutamicum CP.

Keywords: ultrasound; L-leucine; fermentation; Corynebacterium glutamicum; response surface methodology; fed-batch culture 


\section{Introduction}

L-leucine, a branched-chain amino acid, is one of eight essential amino acids that cannot be synthesized by mammals [1]. It plays an important role in physiological functions and metabolism [2,3]. L-leucine is found in food, pharmaceutical, cosmetic applications, as a precursor for antibiotics and herbicides, and as a food additive [4]. Generally, L-leucine is produced by protein hydrolysis and extraction, chemical synthesis, enzymatic methods, and microbial fermentation. As the market demand for L-leucine increases, fermentation methods have attracted attention due to their economic and environmental friendliness.

The most common bacteria used for L-leucine production via fermentation, are Corynebacterium glutamicum and Escherichia coli [5, 6]. In early stages, most Lleucine production strains were isolated by random mutagenesis and selection. However, the random mutagenesis approach distributes genetic alterations throughout the chromosome, which are difficult to identify and may cause unexpected effects such as unwanted modifications, growth retardation, by-product formation, and unstable genetic phenotypes [7]. Recently, L-leucine-producing strains have been developed by targeted genetic manipulation to avoid this problem. Highly productive strains can be created in a genetically defined manner through improving the supply of precursors, releasing feedback inhibition and repression, blocking competing pathways, and overexpressing biosynthetic genes responsible for target amino acids [4, 8, 9]. Various studies related to the metabolic engineering of microbial cells toward L-leucine have been reported. With the wide type of $C$. glutamicum taken as the chassis strain, an efficient L-leucine production strain, MV-LeuF2, was developed using rational metabolic engineering, which accumulates L-leucine to levels exceeding $24 \mathrm{~g} / \mathrm{L}$ under fed-batch culture conditions [10]. Wang et al. engineered C. glutamicum to enhance Lleucine production by improving the redox flux and modification of carbon metabolism $[11,12]$.

Although great strides have been made in the development of L-leucine-producing bacteria, process engineering control and technology is essential to maximize the production performance of the strains and improve yields. Ultrasound technology, as a novel non-thermal physical processing technique, has been widely used in the food industry, especially in fermentation engineering [13, 14]. Moreover, Ultrasound technology is a process intensification that is defined as any technological development that leads to a safer, cleaner, and more energy-efficient process. In fact, ultrasound has a dual effect on microorganisms, lethally affecting or stimulating growth depending on the intensity and frequency of ultrasound application [15]. Ultrasound can alter the metabolic activity of microbial cells, resulting in accelerating proliferation, increasing metabolites, increasing enzyme production, and increasing membrane permeability [16, 17]. The positive effect of low-intensity ultrasound on biofilm formation has been reported to increase the hydrophobicity and membrane permeability of biofilm-forming microorganisms by increasing the delivery of oxygen and nutrients to the deeper layers of biofilms [18, 19].

The beneficial effects of ultrasound on bioprocesses have been reported for several microorganisms. In general, gram-positive bacteria have a higher resistance to 
ultrasound technology than gram-negative bacteria due to the characteristic cell wall, which is thicker and more robust in the former due to the cross-linking of teichoic acid and peptidoglycans [20]. The acetone-butanol-ethanol (ABE) yield of an ultrasoundassisted fermentation process using Clostridium acetobutylicum MTCC 11274 was $0.288 \mathrm{~g} / \mathrm{g}$ raw biomass in $92 \mathrm{~h}$ compared with a yield of $0.168 \mathrm{~g} / \mathrm{g}$ raw biomass in 120 $\mathrm{h}$ with mechanical agitation [21]. Ultrasonic treatment can increase the production rate of GSH by $S$. cerevisiae during fermentation [22]. Furthermore, ultrasonic treatment had little effect on the survival ratio of algal cells but could promote the permeability and substrate utilization of mixotrophic microalgae, resulting in a significant increase in lipid accumulation and biomass [23]. Ultrasonic treatment has drawn the attention of many researchers due to its prospects for application in fermentation engineering.

In this study, we used sonication as a medium to intensify the L-leucine fermentation process. We investigated the effects of different ultrasound powers, frequencies, intervals, and durations on C. glutamicum CP growth and L-leucine production and obtained the optimum combination by response surface methodology (RSM). We also analyzed the effects of ultrasound on cell morphology, cell membrane permeability, and activity of key enzymes to gain a mechanistic understanding of the enhancement of fermentation induced by ultrasound irradiation. This study aims to develop new strategies for improving L-leucine productivities.

\section{Results and discussion \\ Effect of ultrasonic treatment in different growth phases on biomass of $C$. glutamicum CP}

The growth curve of $C$. glutamicum $\mathrm{CP}$ is plotted in Fig. 1A. The latent phase was $4 \mathrm{~h}$, the logarithmic phase was from $4 \mathrm{~h}$ to $20 \mathrm{~h}$, and the stationary phase was after 20 h of incubation. C. glutamicum CP was incubated for 2, 4, 8, 16, 20, and $24 \mathrm{~h}$. The growth curves corresponded to the latent prophase and anaphase, the logarithmic prophase, metaphase, and anaphase, respectively. The effects of ultrasound treatment on the different growth stages of $C$. glutamicum $\mathrm{CP}$ are shown in Fig. 1. At the beginning of the acclimation phase and logarithmic phase, there was a significant increase in biomass, and at $8 \mathrm{~h}$, the growth of C. glutamicum CP increased by $15.6 \%$ compared to the control. However, ultrasound treatment near and into the stabilization phase resulted in a significant decrease in biomass. This may be because the cell structure of $C$. glutamicum remained intact during the adaptation period, and the ultrasound caused less damage to the body, stimulated its proliferation, and enhanced its adaptability to the culture environment. During the steady period, the density of the bacteria is high, the nutrients in the medium are consumed, harmful metabolites accumulate, and the cell growth rate is almost equal to zero. At this time, the ultrasound treatment accelerates the decay of the cells, resulting in a decrease in biomass compared with the non-ultrasound treatment. As a result, C. glutamicum CP in the logarithmic phase of $8 \mathrm{~h}$ was selected to accept ultrasonic irradiation in the following experiments.

\section{Effect of ultrasound parameters on growth of C. glutamicum $\mathbf{C P}$}

To improve the biomass, single-factor experiments were carried out and the effects 
of different ultrasonic parameters on the growth of C. glutamicum CP were investigated, as shown in Fig. 2. Various ultrasonic powers (50, 100, 150, 200, and $250 \mathrm{~W} / \mathrm{L})$ were designed to investigate the effect of ultrasonic power on cell growth (Fig. 2A). All test powers enhanced the biomass to some degree, except for the power of $250 \mathrm{~W} / \mathrm{L}$. When the ultrasonic power was 50 and $150 \mathrm{~W} / \mathrm{L}$, there was no significant difference in biomass increment. The biomass reached a maximum with an increase of $21.5 \%$ over the control under an ultrasonic power of $100 \mathrm{~W} / \mathrm{L}$. This indicates that lower ultrasonic power can stimulate $C$. glutamicum $\mathrm{CP}$ growth, whereas over-stimulation by ultrasonic treatment with intensified power might result in cell damage. Thus, the ultrasonic power of $100 \mathrm{~W} / \mathrm{L}$ was employed in the following experiments. Ultrasonic that frequencies were too high or too low had negative effects on the growth of microorganisms. Under the ultrasonic frequency of $25 \mathrm{kHz}$, the biomass reached a maximum with an increase of $17.5 \%$ compared with no ultrasonic treatment. Depending on the ultrasound frequency used, transient or stable cavitation is generated in the liquid medium. When the low frequency ultrasound within $20-100 \mathrm{kHz}$ is used, the transient cavitation occurs. At high frequencies over $200 \mathrm{kHz}$, stable cavitation is observed, resulting in the regular oscillation between high and low acoustic pressure for thousands of cycles. As indicated in previous reports, megahertz frequency ultrasound resulted in no cavitation [24, 25]. Considering the high biomass, $25 \mathrm{kHz}$ was chosen as the optimal ultrasonic frequency in the present work.

It is very important to set a certain time interval for the process of ultrasonic treatment because serial ultrasonic treatment may cause irreversible damage to cells and instruments [26]. Several studies have reported the influence of ultrasonic pulsed models on the growth of microorganisms. It was found that the ultrasonic pulsed model of on time $100 \mathrm{~s}$ and off time $10 \mathrm{~s}$ under the conditions of $28 \mathrm{kHz}, 100 \mathrm{~W} / \mathrm{L}$ for $0.5 \mathrm{~h}$ of sonication time showed the highest increase in the peptide content and viable cell count compared with the control [27]. Ren et al. optimized the ultrasonic interval to improve the biomass and lipid accumulation of mixotrophic microalgae [23]. The ultrasonic interval had a great influence on the growth of C. glutamicum CP. The biomass of bacteria decreased significantly with shorter ultrasonic intervals. A maximum biomass increment of $12.7 \%$ was obtained when the ultrasonic interval was $30 \mathrm{~min}$. Furthermore, the increment of C. glutamicum CP biomass with sonication treatment reached maximum when the ultrasonic duration was $40 \mathrm{~s}$.

\section{Modeling L-leucine production with ultrasound treatment}

Response surface methodology (RSM) is an effective and commonly used mathematical optimization tool owing to the simultaneous analysis of interactions of several operating parameters with few experimental trials [28]. The Box-Behnken design is a spherical type design; it consists of a central point and middle points of the edges of the cube circumscribed on the sphere [29]. Furthermore, through RSM analysis and its verification experiments, a reasonably accurate empirical model was established to investigate and predict the relationship between independent variables and the yield of yogurt peptides [27]. Experimental modeling results for L-leucine production are shown in Table $\mathrm{S} 2$. The $\mathrm{R}^{2}$ value, $\mathrm{F}$ value, and $\mathrm{P}$ value were determined for use in 
evaluating the mutual interaction of the independent and dependent variables (Table S3). A second-order polynomial model (Eq. (1)) fitted the experimental data well, with $\mathrm{R}^{2}$ values of 0.9747 , which suggested that the models were significant and could be used to optimize the ultrasonic conditions of L-leucine fermentation. The model was highly significant $(\mathrm{P}<0.01)$, and the lack of fit indicated a good correlation with the model data $(\mathrm{P}<0.05)$. Furthermore, the coefficient of variance $(\mathrm{CV})$, which represents the dispersion degree of the data, was rather low $(\mathrm{CV}<10 \%)$ in the model. This further supports the good fit of the model, and thus, provides better reproducibility. The secondorder polynomial Eqns. (2) describes the relationship between ultrasonic powers (A), frequencies (B), interval (C), and duration (D). E represents scientific notation (E).

$$
\begin{array}{r}
Y=-526.26592+0.80385 A+27.23841 B+4.79884 C+5.99755 D-0.012437 A B \\
+0.012781 A C-1.94466 E-003 A D-0.070948 B C-0.036414 B D-9.12218 E-003 C D \\
-4.37387 E-003 A^{2}-0.43179 B^{2}-0.060933 C^{2}-0.060604 D^{2}
\end{array}
$$

\section{Optimization of ultrasonic conditions by RSM analysis}

Using the regression evaluation, the four independent variables showed a linear effect on the production of L-leucine with ultrasonic processing. As shown in Table S3, L-leucine was significantly affected by ultrasonic power, frequency, interval, and duration at the level of $\mathrm{P}<0.01$. All quadratic terms were significant at $\mathrm{P}<0.01$. The interaction of $\mathrm{AB}, \mathrm{AC}$, and $\mathrm{BC}$ was statistically significant at $\mathrm{P}<0.05$, while the interaction of $\mathrm{AD}, \mathrm{BD}$, and $\mathrm{CD}$ was not significant $(\mathrm{P}>0.05)$. Near the midpoint of the response plot, the L-leucine titers reached their highest. The influence of these four variables on L-leucine formation was further analyzed by three-dimensional plots of RSM models (graphical representations of the regression model). A moderate interaction between these assigned variables was characterized by the shape of the response surface curves. These response surface plots made it convenient to understand the interactions between any two factors and to locate their optimum levels. The Lleucine titer was observed as a response variable to the interaction of the ultrasonic power versus frequency, and the rest of the two parameters were at central values. Furthermore, the L-leucine titer could be obtained at an optimal value of ultrasonic power and frequency. L-leucine production was enhanced at the ultrasonic power and frequency of central levels (Fig. 3A). The same course of the remaining factors (Fig. $3 \mathrm{~B}-\mathrm{F}$ ) indicated that the optimal value of each parameter could be obtained. RSM has also been used in other ultrasound studies. For instance, under the optimal conditions carried out by RSM, the specific rate of the cis-epoxysuccinate hydrolase reached $194.79 \pm 1.78 \mathrm{mM} / \mathrm{h} / \mathrm{g}$, which was 4-fold higher than that in the control [30]. RSM coupled with Box-Behnken design has been chosen to find relations between the responses (in vitro angiotensin-I-converting enzyme inhibitory activity, peptide content, and biomass of B. subtilis) and some ultrasonic parameters [31].

The optimal conditions for L-leucine production were obtained by applying the prediction profiler model with the following data: ultrasonic power of $94.00 \mathrm{~W} / \mathrm{L}$, frequency of $25.47 \mathrm{kHz}$, interval of $31.13 \mathrm{~min}$, and duration of $37.04 \mathrm{~s}$. Under the optimal ultrasonic condition, the maximum predicted values of the L-leucine titer were 
$53.36 \mathrm{~g} / \mathrm{L}$. The experiments were performed in triplicate for validation of the model. The ultrasound treatment at the optimized conditions started at $8 \mathrm{~h}$ of fed-batch fermentation. The experimental conditions were ultrasonic power of $94.00 \mathrm{~W} / \mathrm{L}$, ultrasonic frequency of $25 \mathrm{kHz}$, ultrasonic interval of $31 \mathrm{~min}$, and ultrasonic duration of $37 \mathrm{~s}$. The biomass and L-leucine concentrations in the ultrasonic experiments were significantly higher than those in the control. The L-leucine titer was $52.89 \mathrm{~g} / \mathrm{L}$, which was about 1.21-fold higher than that in the control $(43.5 \mathrm{~g} / \mathrm{L})$, which was similar to its predicted value $(53.36 \mathrm{~g} / \mathrm{L})$ according to the equation. The errors between the predicted and experimental values $<2 \%$. Thus, we extrapolated that the regression models obtained by RSM could predict L-leucine production by any combination of independent sonication variables.

Due to the vigorous growth of cells, the nutrient and oxygen mass transfer rate increasing, the glucose consumption rate under the ultrasound treatment was faster than that of the control. L-leucine yield from glucose and productivity under ultrasound treatment were $0.30 \mathrm{~mol} / \mathrm{mol}$ and $1.2 \mathrm{~g} / \mathrm{L} / \mathrm{h}$, respectively, which were $8.2 \%$ and $14.2 \%$ higher than that in the control, respectively. In brief, ultrasound can improve the fermentation profile and productivity properties of L-leucine by increasing the viability, membrane permeability, and enzyme activity of the microbial cells. Therefore, ultrasound can be applied to L-leucine production processing if optimum ultrasonication parameters are carefully determined before applying sonication. According to extensive research, proper ultrasonic power density could increase the growth rate by improving the membrane fluidity and permeability of microorganisms, while excessive ultrasound treatment would cause the cell damage, as a result, biomass decreased accordingly. The existence of an optimal ultrasonic power density has also been reported earlier by other researchers [27, 32]. In addition, cavitation is known to produce a series of mechanical effects, such as particle collisions and cell wall disruption, which promote penetration of the solvent into the sample matrix and increase the mass transfer rates of anthocyanins [33]. The ultrasonic power could weaken the cell wall [25], increasing the contact between anthocyanins and solvent, which brought about a reduction of the sonication time. Ultrasonication has been applied to accelerate the fermentation process and improve the cell growth of $S$. cerevisiae, resulting in the formation of substances in the fermentation system [32].

\section{Effect of ultrasonic treatment on the micrograph of $C$. glutamicum CP}

SEM is widely applied to investigate the surface characterization, morphology, and ultrastructure of microorganisms. For instance, Lee et al. founded that the $C$. ammoniagenes $\triangle$ ramA mutant exhibits an elongated cell shape, which might relate to the decrease of cell wall-associated proteins as the ramA was knocked out [34]. After ultrasonic treatment, the surface of algal cell wall exhibited tiny cracks or holes, but the algal cell did not break and still had complete structure [23]. Therefore, we examined the effect of ultrasonic treatment on the cell morphology by SEM. When C. glutamicum $\mathrm{CP}$ grew to a stationary phase, a small amount of fermentation broth was removed to obtain the bacteria, which were fixed, dehydrated, and then observed by SEM. $C$. glutamicum CP cells showed a typical asymmetric rod shape, and V-shaped cell pairs 
were observed frequently (Fig. 5). However, there were more irregular, elongated, and swollen cells under the ultrasonic condition than that under the control. After lowstrength ultrasonic treatment, $C$. glutamicum $\mathrm{CP}$ can survive and maintain the integrity of their cell structures. The cell wall plays an important role in cell permeability, with a variety of important functions, including maintenance of cell shape, protection from mechanical damage, and generation of turgor by restraining the outward osmotic pressure exerted on the cytoplasmic membrane. Studies have shown that the structural function of the cell membrane and cell wall improves intracellular synthesis and secretion processes simultaneously [35-37]. SEM images of untreated and treated samples could provide insights into the growth and metabolism of C. glutamicum CP.

\section{Effect of ultrasonic treatment on cell permeability}

The cell membrane can isolate the environment inside and outside the cell and plays an important role in reproduction, energy transfer, and substance metabolism [38]. It is the first line of defense for cells to be persecuted by the external environment or treatment. To determine whether ultrasonic treatment affects the integrity of the $C$. glutamicum CP cell membrane, fluorescence microscopy together with LIVE/DEAD BacLight Bacterial Viability Kits were used. With an appropriate mixture of SYTO 9 and PI stains, cells with intact membranes stain fluorescent green, whereas bacteria with damaged membranes stain fluorescent red [39]. As shown in Fig. 6, under ultrasound treatment, the number of cells that emitted a green fluorescence were reduced compared with those without ultrasound treatment, while the number of cells emitting a red fluorescence increased. This indicated that the C. glutamicum CP cell membrane was destroyed to some extent under ultrasound treatment, which was beneficial to L-leucine production due to enhancing L-leucine transport. Ultrasonic stimulation can improve the permeability of the membrane, which affects the transport of nutrients, resulting in the variation of cell activity and intracellular compound synthesis [26, 40]. However, a high level of sonoporation can lead to leakage of cellular content due to physical disruption and modification of the membrane lipid bilayer, resulting in cell death. Therefore, ultrasound process parameters must be truly quantified and controlled to achieve the desired level of cell permeability [25, 41, 42]. In addition to direct microbubble contact, microstreaming around cavitating microbubbles provides a second possible origin of mechanical stress on the cellular membrane influencing permeability [41]. Moreover, stable microbubble oscillations can induce the formation of free radicals and molecular products such as $\mathrm{H}_{2} \mathrm{O}_{2}$, which play a crucial role in lipid bilayer reposition and membrane disruption by lipid peroxidation [43, 44]. Furthermore, the peroxidation of membrane lipids and location of proteins to the surface of the cell membrane increases membrane fluidity and membrane permeabilization upon ultrasound treatment $[45,46]$. Another reason for membrane permeability enhancement could be acoustic cavitation, which is a mechanism underlying the mechanical effects of ultrasound irradiation [47].

\section{Effect of ultrasonic treatment on the activity of enzymes}

Acetohydroxyacid synthase (AHAS) and isopropylmalate synthase (IPMS) 3- 
isopropylmalate dehydratase (IPMD) are key enzymes in the L-leucine biosynthetic pathway in bacteria. In C. glutamicum, only one AHAS is encoded by ilvBN. The leuA gene encodes IPMS, and the leuCD genes encode IPMD [48]. C. glutamicum CP cells from the stationary phase of the fed-batch culture with/without ultrasound were collected to study the effect of ultrasonic treatment on enzyme activity, as shown in Fig. 7. The relative activity of AHAS under ultrasonication was not significantly different from that of the control. The relative activity of IPMS and IPMD under ultrasonication represented a significant increase of $8.9 \%$ and $18.2 \%$ over the control, respectively. Under suitable conditions, ultrasound changes the conformation of the enzyme to accelerate the contact between the enzyme and substrate, generating cavitation, magnetostrictive, and mechanical oscillation effects. Thus, bioactive molecules become involved and the biological activity of enzymes is promoted [16, 25, 41]. The catalytic activity of the enzyme strongly depends on the configuration of the active site. Ultrasonic treatment could induce changes in its secondary structure, which could lead to better exposure of the enzyme's active sites [49]. Moreover, ultrasound can alter the characteristics of substrates and thereby reactions between enzymes and substrates. It can also provide an optimal environment for the reactions. Several studies have reported on the effect of ultrasonic treatment on enzyme activity. With ultrasound $(20 \mathrm{kHz}$, amplitude at 20\%) to irradiate on L. acidophilus BCRC 10695 during the stationary phase of growth for $2 \mathrm{~min}$ and $24 \mathrm{~h}$ of re-incubation, the beta-glucosidase activity was enhanced to $3.91 \mathrm{U} / \mathrm{mL}$, which was 1.82 times higher than that without ultrasound treatment [50]. The conformational and residual activity changes of enzymes under ultrasound conditions were evaluated [51].

\section{Conclusion}

Herein, four factors of ultrasound conditions, including power densities, frequencies, intervals, and duration, were investigated to obtain the optimum conditions to produce L-leucine by C. glutamicum CP in fed-batch culture, and the regression models obtained by RSM were used to predict L-leucine production. The enhancement of L-leucine production was attributed to intense micro-mixing induced by sonication, which has several possible implications on cell morphology, cell membrane permeability, and enzyme activity. This study provides a theoretical basis and technological support for better understanding and choosing ultrasonic conditions to produce L-leucine in the fermentation industry.

\section{Materials and methods \\ Strain and culture media}

C. glutamicum CP, a leucine-producing strain, was obtained through multiple rounds of random mutation and screening and was deposited at the China General Microbiological Culture Collection Center under the accession number CGMCC 11425. The complete genome sequence of $C$. glutamicum $\mathrm{CP}$ was reported by Gui et al. [52].

The medium used for seed culture contained (per liter): $40 \mathrm{~g}$ glucose, $40 \mathrm{~g}$ corn steep liquor (CSL), $2 \mathrm{~g} \mathrm{KH}_{2} \mathrm{PO}_{4} \cdot 12 \mathrm{H}_{2} \mathrm{O}, 2 \mathrm{~g} \mathrm{MgSO}_{4} \cdot 7 \mathrm{H}_{2} \mathrm{O}, 5 \mathrm{mg} \mathrm{FeSO} 4 \cdot 7 \mathrm{H}_{2} \mathrm{O}, 0.2 \mathrm{~g}$ L-methionine, $0.3 \mathrm{~g}$ L-isoleucine, $0.5 \mathrm{mg}$ biotin, and $0.2 \mathrm{mg}$ thiamine. 
The fermentation medium consisted of (per liter): $100 \mathrm{~g}$ glucose, $20 \mathrm{~g} \mathrm{CSL}, 2 \mathrm{~g}$ $\mathrm{KH}_{2} \mathrm{PO}_{4} \cdot 12 \mathrm{H}_{2} \mathrm{O}, 3 \mathrm{~g} \mathrm{MgSO} \cdot \cdot 7 \mathrm{H}_{2} \mathrm{O}, 30 \mathrm{mg} \mathrm{MnSO} \cdot \mathrm{H}_{2} \mathrm{O}, 30 \mathrm{mg} \mathrm{FeSO} \cdot \cdot 7 \mathrm{H}_{2} \mathrm{O}, 0.2 \mathrm{~g} \mathrm{~L}-$ methionine, $0.3 \mathrm{~g} \mathrm{~L}$-isoleucine, $2 \mathrm{~g} \mathrm{~L}$-glutamic acid, $0.3 \mathrm{mg}$ biotin, and $0.3 \mathrm{mg}$ thiamine. All media were adjusted to a $\mathrm{pH}$ of 7.2 with $\mathrm{NaOH}$. All reagents were purchased from Sigma-Aldrich (China).

\section{Fed-batch cultivation}

Fed-batch cultivations were performed in a 30-L fermenter (Baoxing Biological Equipment Engineering Co., LTD, Shanghai, China). Bacterial growth was monitored by measuring the optical density at $600 \mathrm{~nm}\left(\mathrm{OD}_{600}\right)$. The seed culture was transferred to bioreactors at the indicated inoculum size when the cells were in the mid-exponential phase $\left(\mathrm{OD}_{600}=15-20\right)$. The culture was aerated at a rate of $0.6 \mathrm{vvm}$ (volume per volume and minute) with filtered air and maintained at $32^{\circ} \mathrm{C}$. The stirrer speed, ventilation ratio, and bioreactor inner pressure were varied while keeping the dissolved oxygen saturation (DO) at $20-30 \%$. The $\mathrm{pH}$ was kept constant at $7.0-7.2$ by the automatic addition of ammonium hydroxide $(25 \%, \mathrm{v} / \mathrm{v})$. Antifoam was added to the bioreactor to prevent foam formation when necessary. When the concentration of glucose in the medium was reduced to $10 \mathrm{~g} \mathrm{~L}^{-1}$, feed solution $(80 \%$ glucose, w/v) was added to maintain a concentration of approximately $5 \mathrm{~g} \mathrm{~L}^{-1}$ in the feed phase.

\section{Determination of the optimum ultrasonic treatment scheme}

In this section, the fermentation system consisted of a fermenter and multifrequency power ultrasonic equipment (Handan Haituo Machinery Technology Co. LTD, Hebei, China). The ultrasonic system included an ultrasound generator, transducer, and probe which was equipped to the bottom of the fermenter (Fig. S1). It was employed to study the influence of ultrasound treatment on the bacterial growth of $C$. glutamicum CP. The single factor experiment included two parts: exploring the effect of ultrasound on growth phases and the effects of ultrasonic power $(50-250 \mathrm{~W} / \mathrm{L})$, frequency $(15-40 \mathrm{kHz})$, interval (10-50 min), and duration (20-60 s) on the growth of C. glutamicum CP.

\section{RSM analysis of the optimum ultrasonic treatment scheme on the production of L-leucine}

The production of L-leucine was performed in a growth-coupled process, so the optimum ultrasonic conditions for L-leucine formation were based on single factor experiments described above. The influence of ultrasonic power, frequency, interval, and duration on L-leucine in the optimum scheme of ultrasonic treatment with the most efficient fermentation was investigated using RSM. The experimental design and statistical analysis were performed using the Design Expert statistical software (version 8.0.6, Stat-Ease, Inc., USA). To evaluate the influence of the parameters and their interactive effects on the response surface in the region of investigation, a three-level, four-factor Box-Behnken design was employed. The experimental variables were investigated at three levels $(-1,0,+1)$. The range and levels of these independent variables are presented in Table S1. The titer of L-leucine produced by C. glutamicum 
$\mathrm{CP}$ was selected as the response vector, $\mathrm{Y}(\mathrm{g} / \mathrm{L})$. The response variables were fitted to the following second-order polynomial model equation (Eq. (1)), which describes the relationship between the responses and the independent variables.

$$
\begin{aligned}
& \mathrm{Y}=\beta_{0}+\mathrm{A} \beta_{1}+\mathrm{B} \beta_{2}+\mathrm{C} \beta_{3}+\mathrm{D} \beta_{4}+\mathrm{AB} \beta_{5}+\mathrm{AC} \beta_{6}+\mathrm{AD} \beta_{7}+\mathrm{BC} \beta_{8}+\mathrm{BD} \beta_{9}+\mathrm{CD} \beta_{10} \\
& +\mathrm{A}^{2} \beta_{11}+\mathrm{B}^{2} \beta_{12}+\mathrm{C}^{2} \beta_{13}+\mathrm{D}^{2} \beta_{14}
\end{aligned}
$$

Where $\mathrm{Y}$ is the response (L-leucine titer), $\mathrm{A}$ is the ultrasound powers, $\mathrm{B}$ is the ultrasound frequencies, $C$ is the ultrasound intervals, $D$ is the ultrasound durations, $\beta_{0}$ is a constant, $\beta_{1}-\beta_{4}$ are linear coefficients, $\beta_{5}-\beta_{10}$ are interaction coefficients between the factors, and $\beta_{11}-\beta_{14}$ are quadratic coefficients.

\section{Analytical methods}

Fermentation broth samples $(5 \mathrm{~mL})$ were retrieved every $4 \mathrm{~h}$ for analysis. Cell growth was determined by detecting changes in dry cell weight (DCW) as described previously [53].

The detection and quantification of glucose in the culture supernatants was performed using an SBA-40E immobilized enzyme biosensor (Biology Institute of Shandong Academy of Sciences, Jinan, China). Amino acid concentrations were measured by high-performance liquid chromatography (HPLC) using an LC20AT system (Shimadzu, Kyoto, Japan) equipped with an Agilent ZORBAX Eclipse AA column $(4.6 \times 150 \mathrm{~mm}, 5 \mu \mathrm{m}$; Agilent Technologies, Palo Alto, CA, USA) with UV detection $(360 \mathrm{~nm})$. Acetate-buffered acetonitrile was used as the mobile phase at a flow rate of $1 \mathrm{~mL} / \mathrm{min}$ [54]. All data were measured in triplicates.

\section{Preparation of crude enzyme solution and determination of enzyme activity}

The crude enzyme solution was prepared to determine the enzyme activities of AHAS, IPMS, and IPMD. The cells were collected by centrifugation $(8000 \times g, 10 \mathrm{~min}$, $4{ }^{\circ} \mathrm{C}$ ) and washed with $50 \mathrm{mM}$ Tris- $\mathrm{HCl}(\mathrm{pH}$ 7.4). Then, the resuspended cells were sonicated and centrifuged $\left(40,000 \times \mathrm{g}, 30 \mathrm{~min}, 4{ }^{\circ} \mathrm{C}\right)$ to remove cell debris. The supernatant constituted the crude enzyme solution. The protein concentration was determined using the BCA Protein Assay Kit (Solarbio, Beijing, China). Protein concentration and enzyme activity were measured in triplicate.

The AHAS was determined according to a published method [55]. One unit of enzyme activity was defined as the amount of enzyme required to produce $1 \mu \mathrm{mol}$ of acetolactate per minute under the optimal reaction conditions of the assay.

The IPMS enzyme activity was determined by detecting coenzyme A formation using Ellmann's reagent [10]. One unit of enzyme activity was defined as the amount of enzyme that converts $1 \mu \mathrm{mol}$ of $\alpha$-isopropylmalate per min under the optimal reaction conditions of the assay.

IPMD enzyme activity was determined by detecting the production of the reaction intermediate $\alpha$-isopropylmaleate [10]. One unit of enzyme activity was defined as the amount of enzyme that converts $1 \mu \mathrm{mol} \alpha$-isopropyl maleate per min under the optimal reaction conditions of the assay. 


\section{Scanning electron microscopy (SEM) analyses of C. glutamicum CP}

Fermentation broth samples with or without ultrasonic treatment were centrifuged at $8000 \times g$ for $10 \mathrm{~min}$. After removing the supernatant, the cell pellet was washed with a $0.85 \% \mathrm{NaCl}$ solution three times and then resuspended and soaked in $4 \%$ glutaraldehyde solution for $3 \mathrm{~h}$. After separation by centrifugation, the bacteria were rinsed with $0.85 \% \mathrm{NaCl}$ solution three times and further dehydrated using 50\%, 70\%, $90 \%, 95 \%$, and $100 \%$ ethanol. The samples were dried at $37{ }^{\circ} \mathrm{C}$ for $3 \mathrm{~h}$. The bacteria were adhered to the sample stubs with conductive carbon tape, followed by sputter coating with gold before the scanning process using an Oxford instrument (JEOL JSM5800LV, Japan) with a $10 \mathrm{kV}$ beam.

\section{Cell membrane permeability}

LIVE/DEAD ${ }^{\circledR}$ BacLight $^{\mathrm{TM}}$ Bacterial Viability Kits L7012 (Thermo Fisher, USA) were used for bacterial cell staining according to the protocol. The kit consisted of SYTO 9 dye and propidium iodide (PI), which both stain nucleic acids. SYTO 9 stains live cells, those with intact membranes, and those with damaged membranes in green, while PI penetrates only cells with damaged membranes, causing a reduction in the SYTO 9 stain fluorescence when both dyes are present. Prior to analysis, cell suspensions at their stationary phase were washed three times and resuspended in $0.85 \%$ $\mathrm{NaCl}$ solution. Equal volumes of dye mixture were added to the bacterial suspension. Then, the compound was mixed thoroughly and incubated at room temperature in the dark for $15 \mathrm{~min}$. Stained cells were scanned using a fluorescence microscope equipped with a relevant filter (Olympus BX53, Japan).

\section{Statistical analysis}

Design Expert 8.0.6 software was used for analysis of the mean responses fitted to a second-order polynomial to obtain regression equations. The adequacy of the polynomial model was evaluated by the coefficient of multiple determinations $\left(\mathrm{R}^{2}\right)$, and analysis of variance (ANOVA) was employed to determine the significance of the model. All the experiments were performed in triplicate and the results were analyzed using SPSS (version 18.0, SPSS, Inc., USA) software. Data normality and homogeneity of variances were tested using Shapiro-Wilk and Levene's tests, respectively. Data were subjected to Duncan's post hoc test. Statistical significance was set at $\mathrm{P}<0.05$. 


\section{Author Contributions}

YZ, QX and NC designed the research; YZ, ZC, and PS performed the experiments; ZC and PS analyzed data; YZ and QX wrote the paper. All authors have approved the final version of the manuscript.

\section{Availability of data and materials}

All data generated or analyzed during this study are included in this published article.

\section{Ethics approval and consent to participate}

Not applicable.

\section{Consent for publication}

Not applicable.

\section{Competing interests}

The authors declare that they have no competing interests.

\section{Acknowledgments}

We would like to thank the members of Bioengineering Comprehensive Laboratory, Tianjin University of science and technology for their great support and contributions throughout this work.

\section{Funding}

This work was financially subsidized by National Key Research and Development Programs of China (Grant. 2018YFA0900300) and Tianjin Synthetic Biotechnology Innovation Capacity Improvement Project (Grant. TSBICIP-KJGG-005). 


\section{References}

1. Wu G: Amino acids: metabolism, functions, and nutrition. Amino Acids 2009, 37:1-17.

2. Yao K, Duan YH, Li FN, Tan B, Hou YQ, Wu GY, Yin YL: Leucine in Obesity: Therapeutic Prospects. Trends Pharmacol. Sci. 2016, 37:714-727.

3. Ikeda T, Morotomi N, Kamono A, Ishimoto S, Miyazawa R, Kometani S, Sako R, Kaneko N, lida M, Kawate N: The Effects of Timing of a Leucine-Enriched Amino Acid Supplement on Body Composition and Physical Function in Stroke Patients: A Randomized Controlled Trial. Nutrients 2020, 12: 1928.

4. Yamamoto K, Tsuchisaka A, Yukawa H: Branched-Chain Amino Acids. Adv. Biochem. Eng./Biotechnol. 2016, 159:103-128.

5. Wendisch VF, Bott M, Eikmanns BJ: Metabolic engineering of Escherichia coli and Corynebacterium glutamicum for biotechnological production of organic acids and amino acids. Curr. Opin. Microbiol. 2006, 9:268-274.

6. Zahoor A, Lindner SN, Wendisch VF: Metabolic engineering of Corynebacterium glutamicum aimed at alternative carbon sources and new products. Comput. Struct. Biotechnol. J. 2012, 3:1-11.

7. Park JH, Lee KH, Kim TY, Lee SY: Metabolic engineering of Escherichia coli for the production of $\mathrm{L}$-valine based on transcriptome analysis and in silico gene knockout simulation. Proc. Natl. Acad. Sci. U. S. A. 2007, 104:7797-7802.

8. Cho JS, Choi KR, Prabowo CPS, Shin JH, Yang D, Jang J, Lee SY: CRISPR/Cas9-coupled recombineering for metabolic engineering of Corynebacterium glutamicum. Metab. Eng. 2017, 42:157-167.

9. Li Y, Wei H, Wang T, Xu Q, Zhang C, Fan X, Ma Q, Chen N, Xie X: Current status on metabolic engineering for the production of L-aspartate family amino acids and derivatives. Bioresour. Technol. 2017, 245:1588-1602.

10. Vogt M, Haas S, Klaffl S, Polen T, Eggeling L, Van JO, Bott M: Pushing product formation to its limit: metabolic engineering of Corynebacterium glutamicum for L-leucine overproduction. Metab. Eng. 2014, 22:40-52.

11. Wang Y-Y, Zhang F, XU J-Z, Zhang W-G, Chen X-L, Liu L-M: Improvement of L-Leucine Production in Corynebacterium glutamicum by Altering the Redox Flux. Int. J. Mol. Sci. 2019, 20: 2020.

12. Wang $Y$ - Y, Shi K, Chen P, Zhang F, Xu J-Z, Zhang W-G: Rational modification of the carbon metabolism of Corynebacterium glutamicum to enhance L-leucine production. J. Ind. Microbiol. Biotechnol. 2020, 47:485-495.

13. Kentish S, Feng H: Applications of Power Ultrasound in Food Processing. In Annu. Rev. Food Sci. Technol., Vol 5. Volume 5. Edited by Doyle MP, Klaenhammer TR. Palo Alto: Annual Reviews; 2014: 263-284.[Annual Review of Food Science and Technology].

14. Chemat F, Zill e H, Khan MK: Applications of ultrasound in food technology: Processing, preservation and extraction. Ultrason. Sonochem. 2011, 18:813-835.

15. Bevilacqua A, Campaniello D, Speranza B, Altieri C, Sinigaglia M, Corbo MR: Two Nonthermal Technologies for Food Safety and Quality-Ultrasound and High Pressure Homogenization: Effects on Microorganisms, Advances, and Possibilities: A Review. J. Food Prot. 2019, 82:2049-2064. 
16. Huang GP, Chen SW, Dai CH, Sun L, Sun WL, Tang YX, Xiong F, He RH, Ma HL: Effects of ultrasound on microbial growth and enzyme activity. Ultrason. Sonochem. 2017, 37:144-149.

17. Dahroud BD, Mokarram RR, Khiabani MS, Hamishehkar H, Bialvaei AZ, Yousefi M, Kafil HS: Low intensity ultrasound increases the fermentation efficiency of Lactobacillus casei subsp.casei ATTC 39392. Int. J. Biol. Macromol. 2016, 86:462-467.

18. Bevilacqua A, Racioppo A, Sinigaglia M, Speranza B, Campaniello D, Corbo MR: A lowpower ultrasound attenuation improves the stability of biofilm and hydrophobicity of Propionibacterium freudenreichii subsp. freudenreichii DSM 20271 and Acidipropionibacterium jensenii DSM 20535. Food Microbiol. 2019, 78:104-109.

19. Erriu M, Blus C, Szmukler-Moncler S, Buogo S, Levi R, Barbato G, Madonnaripa D, Denotti G, Piras V, Orru G: Microbial biofilm modulation by ultrasound: Current concepts and controversies. Ultrason. Sonochem. 2014, 21:15-22.

20. Ojha KS, Mason TJ, O'Donnell CP, Kerry JP, Tiwari BK: Ultrasound technology for food fermentation applications. U/trason. Sonochem. 2017, 34:410-417.

21. Borah AJ, Roy K, Goyal A, Moholkar VS: Mechanistic investigations in biobutanol synthesis via ultrasound-assisted $A B E$ fermentation using mixed feedstock of invasive weeds. Bioresour. Technol. 2019, 272:389-397.

22. Yang Y, Xiang J, Zhang Z, Umego EC, Huang G, He R, Ma H: Stimulation of in situ low intensity ultrasound on batch fermentation of Saccharomyces cerevisiae to enhance the GSH yield. J. Food Process Eng. 2020, 43:e13489.

23. Ren HY, Xiao RN, Kong FY, Zhao L, Xing DF, Ma J, Ren NQ, Liu BF: Enhanced biomass and lipid accumulation of mixotrophic microalgae by using low-strength ultrasonic stimulation. Bioresour. Technol. 2019, 272:606-610.

24. Ashokkumar M, Bhaskaracharya R, Kentish S, Lee J, Palmer M, Zisu B: The ultrasonic processing of dairy products - An overview. Dairy Sci. Technol. 2010, 90:147-168.

25. Akdeniz V, Akalin AS: Recent advances in dual effect of power ultrasound to microorganisms in dairy industry: activation or inactivation. Crit. Rev. Food Sci. Nutr. 2020:1-16.

26. Joyce EM, King PM, Mason TJ: The effect of ultrasound on the growth and viability of microalgae cells. J. Appl. Phycol. 2014, 26:1741-1748.

27. Huang GP, Chen SW, Tang YX, Dai CH, Sun L, Ma HL, He RH: Stimulation of low intensity ultrasound on fermentation of skim milk medium for yield of yoghurt peptides by Lactobacillus paracasei. Ultrason. Sonochem. 2019, 51:315-324.

28. Bibi N, Ali S, Tabassum R: Statistical Optimization of Pectinase Biosynthesis from Orange Peel by Bacillus licheniformis Using Submerged Fermentation. Waste Biomass Valorization 2016, 7:467-481.

29. Sadhukhan S, Sarkar U: Production of Biodiesel from Crotalaria juncea (Sunn-Hemp) Oil Using Catalytic Trans-Esterification: Process Optimisation Using a Factorial and Box-Behnken Design. Waste Biomass Valorization 2016, 7:343-355.

30. Dong WL, Zhao FL, Xin FX, He AY, Zhang Y, Wu H, Fang Y, Zhang WM, Ma JF, Jiang M: Ultrasound-assisted D-tartaric acid whole-cell bioconversion by recombinant Escherichia coli. Ultrason. Sonochem. 2018, 42:11-17.

31. Ruan S, Luo J, Li Y, Wang Y, Huang S, Lu F, Ma H: Ultrasound-assisted liquid-state 
fermentation of soybean meal with Bacillus subtilis. Effects on peptides content, ACE inhibitory activity and biomass. Process Biochem. 2020, 91:73-82.

32. Dai $\mathrm{CH}$, Xiong $\mathrm{F}, \mathrm{He} \mathrm{RH}$, Zhang WW, Ma HL: Effects of low-intensity ultrasound on the growth, cell membrane permeability and ethanol tolerance of Saccharomyces cerevisiae. Ultrason. Sonochem. 2017, 36:191-197.

33. Avhad DN, Rathod VK: Ultrasound assisted production of a fibrinolytic enzyme in a bioreactor. Ultrason. Sonochem. 2015, 22:257-264.

34. Lee SM, Lee JY, Park KJ, Park JS, Ha UH, Kim Y, Lee HS: The Regulator RamA Influences cmytA Transcription and Cell Morphology of Corynebacterium ammoniagenes. Curr. Microbiol. 2010, 61:92-100.

35. Chen RR: Permeability issues in whole-cell bioprocesses and cellular membrane engineering. Appl. Microbiol. Biotechnol. 2007, 74:730-738.

36. Jiang $X$, Wang $H$, Shen R, Chen GQ: Engineering the bacterial Shapes for enhanced inclusion Bodies accumulation. Metab. Eng. 2015, 29:227-237.

37. Elhadi D, Lv L, Jiang XR, Wu H, Chen GQ: CRISPRi engineering E. coli for morphology diversification. Metab. Eng. 2016, 38:358-369.

38. Li B, Tian F, Liu X, Zhao J, Zhang H, Chen W: Effects of cryoprotectants on viability of Lactobacillus reuteri CICC6226. Appl. Microbiol. Biotechnol. 2011, 92:609-616.

39. Shokri S, Shekarforoush SS, Hosseinzadeh S: Efficacy of low intensity ultrasound on fermentative activity intensification and growth kinetic of Leuconostoc mesenteroides. Chem. Eng. Process. 2020, 153:107955.

40. Wang YZ, Xie XW, Zhu X, Liao Q, Chen R, Zhao X, Lee DJ: Hydrogen production by Rhodopseudomonas palustris CQK 01 in a continuous photobioreactor with ultrasonic treatment. Int. J. Hydrogen Energy 2012, 37:15450-15457.

41. Abesinghe AMNL, Islam N, Vidanarachchi JK, Prakash S, Silva KFST, Karim MA: Effects of ultrasound on the fermentation profile of fermented milk products incorporated with lactic acid bacteria. Int. Dairy J. 2019, 90:1-14.

42. Guimaraes JT, Balthazar CF, Scudino H, Pimentel TC, Esmerino EA, Ashokkumar M, Freitas MQ, Cruz AG: High-intensity ultrasound: A novel technology for the development of probiotic and prebiotic dairy products. Ultrason. Sonochem. 2019, 57:12-21.

43. Gao S, Lewis GD, Ashokkumar M, Hemar Y: Inactivation of microorganisms by lowfrequency high-power ultrasound: 1. Effect of growth phase and capsule properties of the bacteria. Ultrason. Sonochem. 2014, 21:446-453.

44. Gao S, Hemar Y, Lewis GD, Ashokkumar M: Inactivation of Enterobacter aerogenes in reconstituted skim milk by high- and low-frequency ultrasound. Ultrason. Sonochem. 2014, 21:2099-2106.

45. Ewe JA, Abdullah WNW, Bhat R, Karim AA, Liong MT: Enhanced growth of lactobacilli and bioconversion of isoflavones in biotin-supplemented soymilk upon ultrasoundtreatment. Ultrason. Sonochem. 2012, 19:160-173.

46. Lentacker I, De Cock I, Deckers R, De Smedt SC, Moonen CTW: Understanding ultrasound induced sonoporation: Definitions and underlying mechanisms. Adv. Drug Delivery Rev. 2014, 72:49-64.

47. Wu J, Nyborg WL: Ultrasound, cavitation bubbles and their interaction with cells. $A d v$. Drug Delivery Rev. 2008, 60:1103-1116. 
48. Franco TMA, Blanchard JS: Bacterial Branched-Chain Amino Acid Biosynthesis: Structures, Mechanisms, and Drugability. Biochemistry 2017, 56:5849-5865.

49. Subhedar PB, Gogate PR: Enhancing the activity of cellulase enzyme using ultrasonic irradiations. J. Mol. Catal. B: Enzym. 2014, 101:108-114.

50. Liu WS, Yang CY, Fang TJ: Strategic ultrasound-induced stress response of lactic acid bacteria on enhancement of beta-glucosidase activity for bioconversion of isoflavones in soymilk. J. Microbiol. Methods 2018, 148:145-150.

51. Rico-Rodriguez F, Serrato JC, Montilla A, Villamiel M: Impact of ultrasound on galactooligosaccharides and gluconic acid production throughout a multienzymatic system. Ultrason. Sonochem. 2018, 44:177-183.

52. Gui $Y, M a ~ Y, X u Q$, Zhang $C$, Xie $X$, Ning $C$ : Complete genome sequence of Corynebacterium glutamicum $\mathrm{CP}$, a Chinese L-leucine producing strain. J. Biotechnol. 2016, 220:64-65.

53. Hou X, Chen X, Zhang Y, Qian H, Zhang W: L-Valine production with minimization of by-products' synthesis in Corynebacterium glutamicum and Brevibacterium flavum. Amino Acids 2012, 43:2301-2311.

54. Ma Y, Chen Q, Cui Y, Du L, Shi T, Xu Q, Ma Q, Xie X, Chen N: Comparative Genomic and Genetic Functional Analysis of Industrial L-Leucine-and L-Valine-Producing Corynebacterium glutamicum Strains. J. Microbiol. Biotechnol. 2018, 28:1916-1927.

55. Choi KJ, Yu YG, Hahn HG, Choi JD, Yoon MY: Characterization of acetohydroxyacid synthase from Mycobacterium tuberculosis and the identification of its new inhibitor from the screening of a chemical library. FEBS Lett. 2005, 579:4903-4910. 


\section{Figure Legends}

Fig. 1. Effect of ultrasound on growth of C. glutamicum CP in different phase. A: The growth curve of C. glutamicum CP; B: biomass increment of C. glutamicum CP cultivated with ultrasound in different incubation time. Different letters indicate significant difference $(\mathrm{P}<0.05)$.

Fig. 2. Effect of ultrasound parameters on growth of $C$. glutamicum CP. Biomass increment of $C$. glutamicum $\mathrm{CP}$ treated with the ultrasound under different powers (A), different frequencies (B), different intervals (C), and different durations (D). Letters indicate significant difference $(\mathrm{P}<0.05)$.

Fig. 3. Response surface plot for interactions between four independent variables on the L-leucine production. The titer of L-leucine was observed as a response variable to the interaction of two independent variables. The remainder of parameters was at central points. Two variables were plotted against each other in each panel.

Fig. 4. Time profiles of biomass (A), glucose (B), and L-leucine (C) concentrations in fed-batch fermentation by $C$. glutamicum $\mathrm{CP}$ in control experiments and ultrasonic experiments. All fermentation experiments were performed with three independent replicates $(\mathrm{n}=3)$.

Fig. 5. Electron microscopic observation of cell morphology of C. glutamicum CP with/without ultrasonic treatment. A-B: control cells; C-D: ultrasound treated cells.

Fig. 6. Fluorescence microscope images of C. glutamicum CP cells with/without ultrasonication. Green-fluorescent bacteria have an intact membrane; red fluorescent bacteria have a permeabilized membrane. A-B: control cells; C-D: ultrasound treated cells.

Fig. 7. Relative activity of AHAS, IPMS, and IPMD in the stationary phase was determined. Data are presented as means \pm standard deviations from three independent experiments. $* \mathrm{P} \leqslant 0.05, * * \mathrm{P} \leqslant 0.01, * * * \mathrm{P} \leqslant 0.001$. 
Fig. 1.
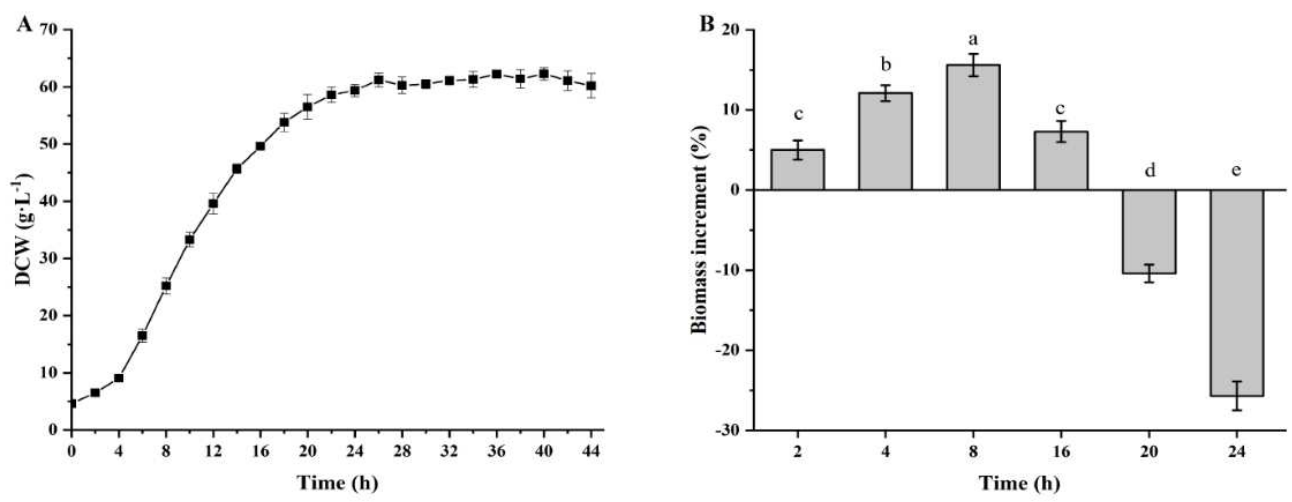
Fig. 2.
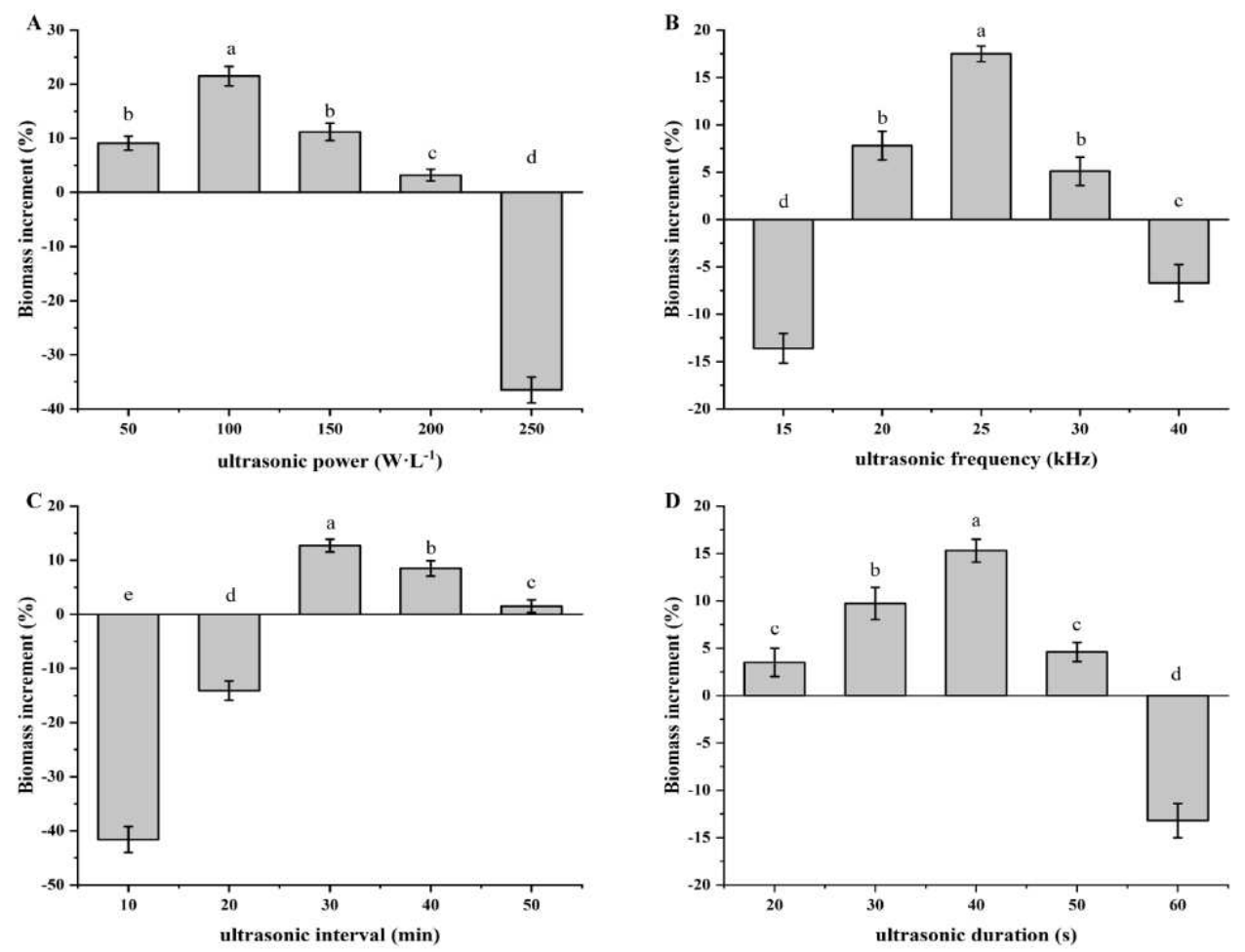
Fig. 3.
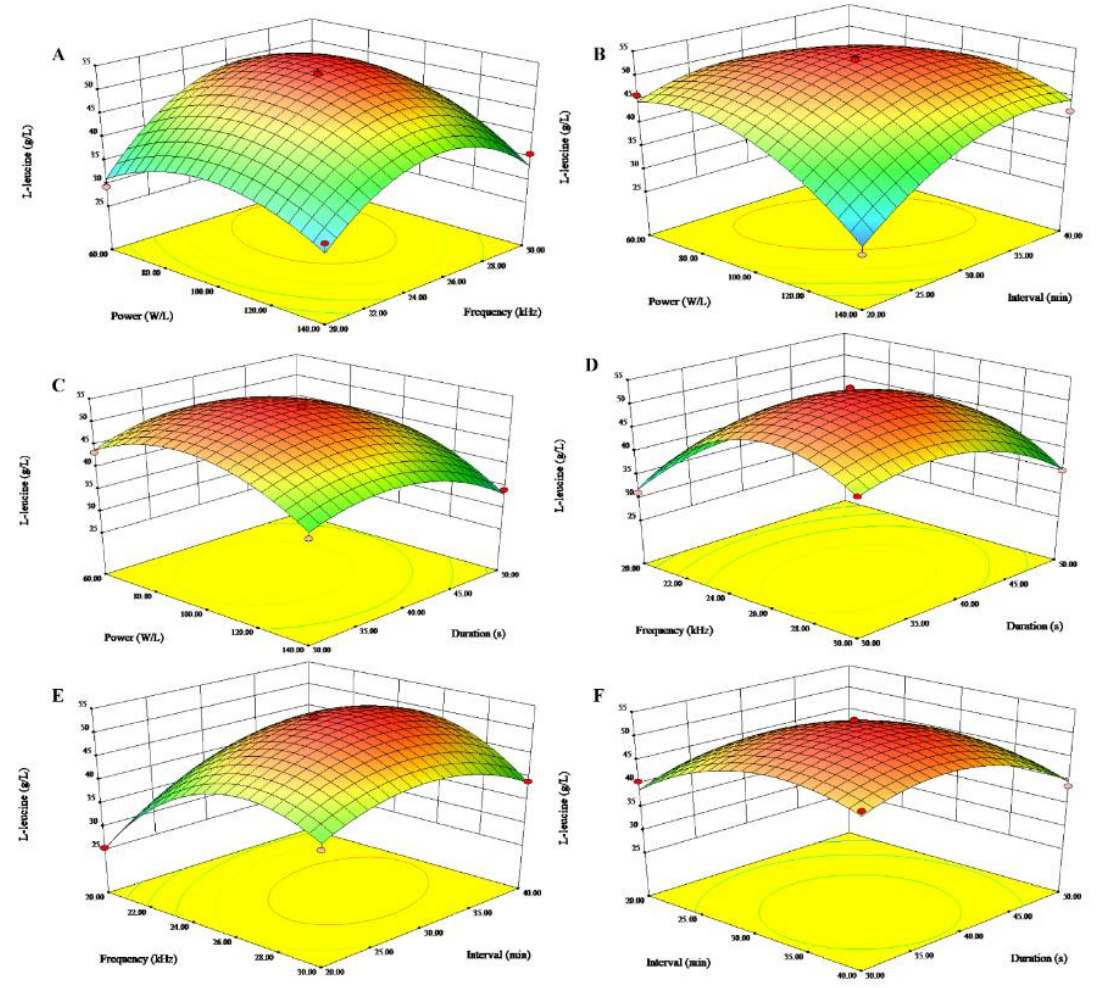
Fig. 4.
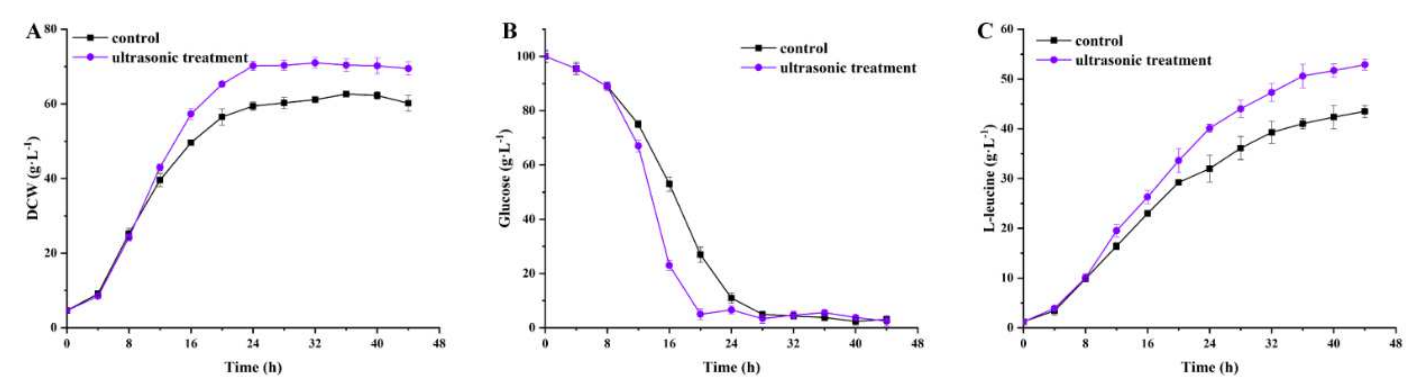
Fig. 5.

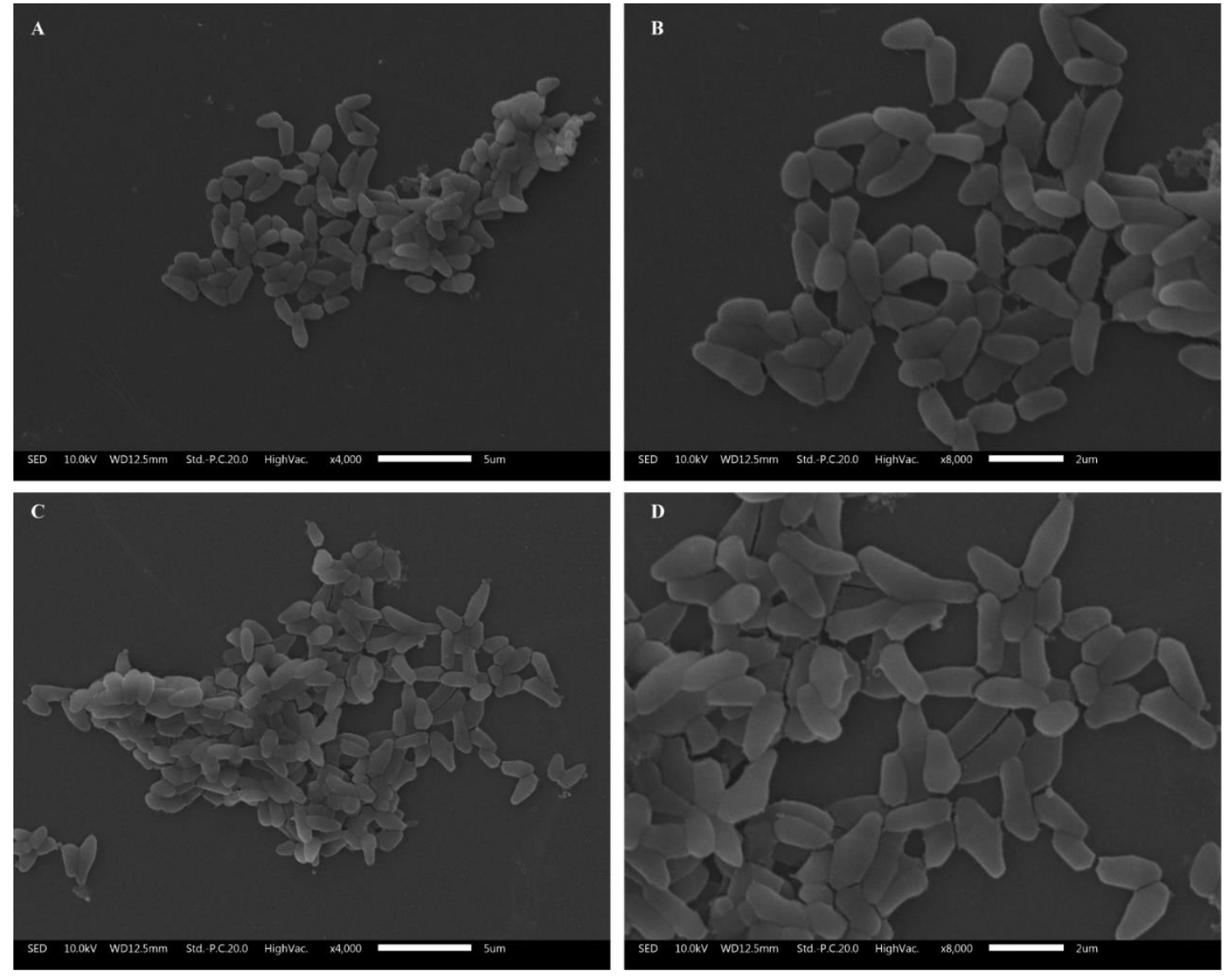


Fig. 6.
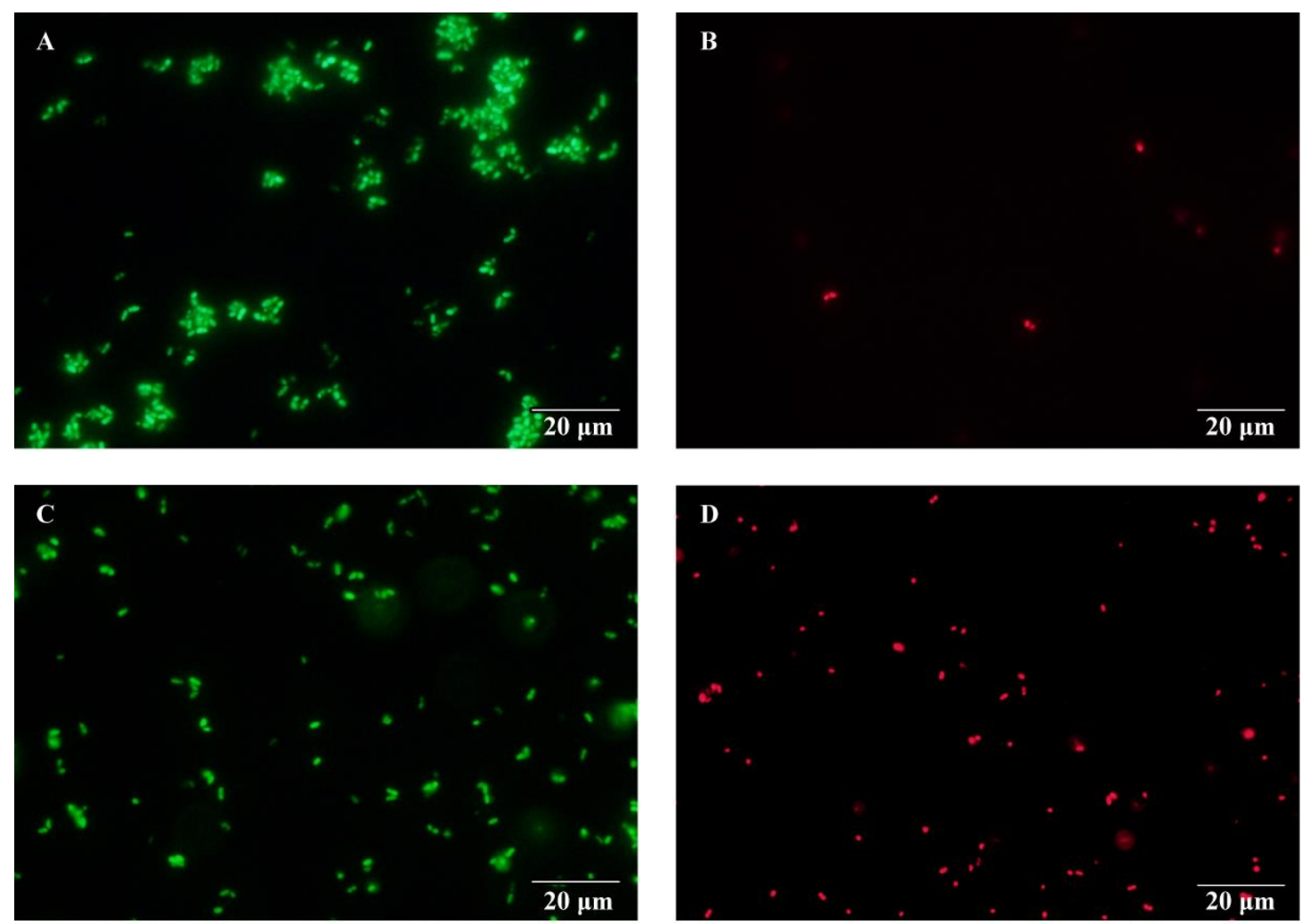
Fig. 7.

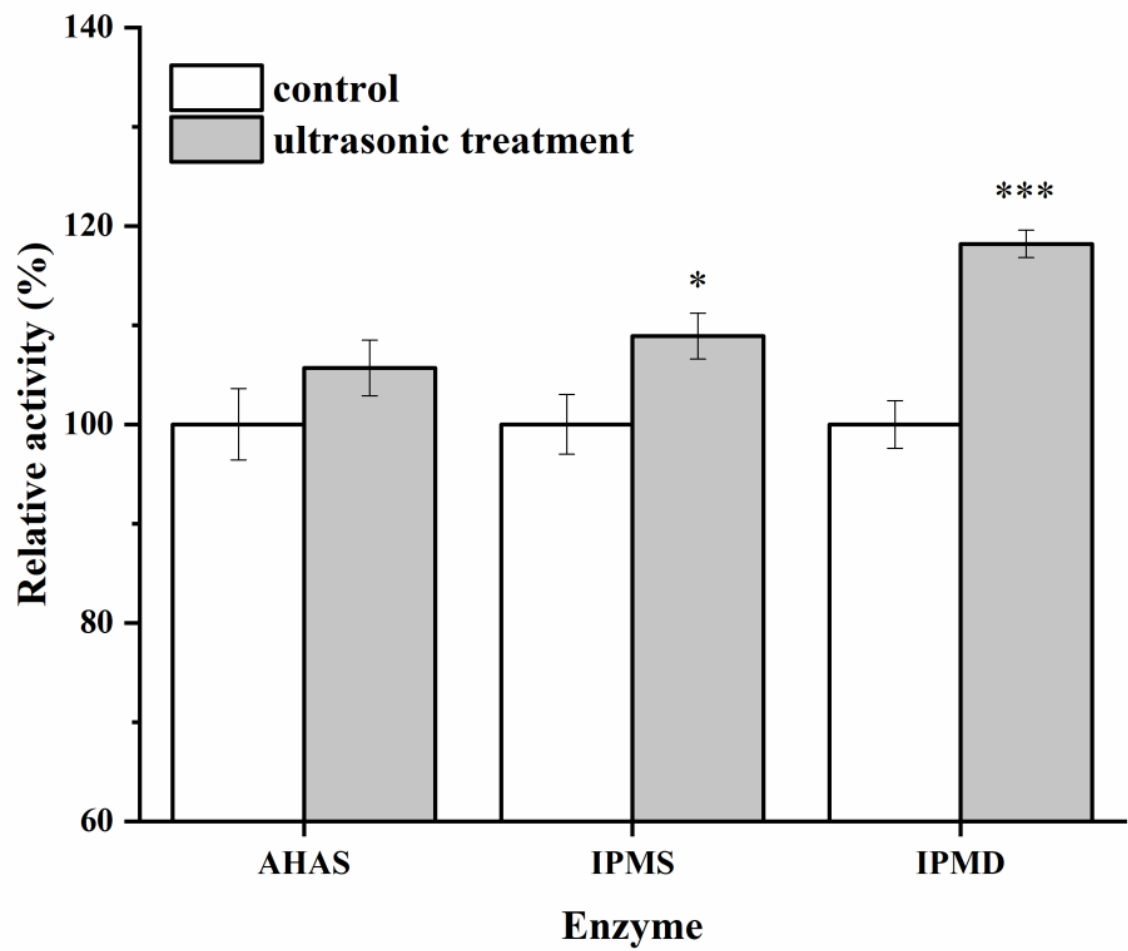


Figures

Fig. 1.
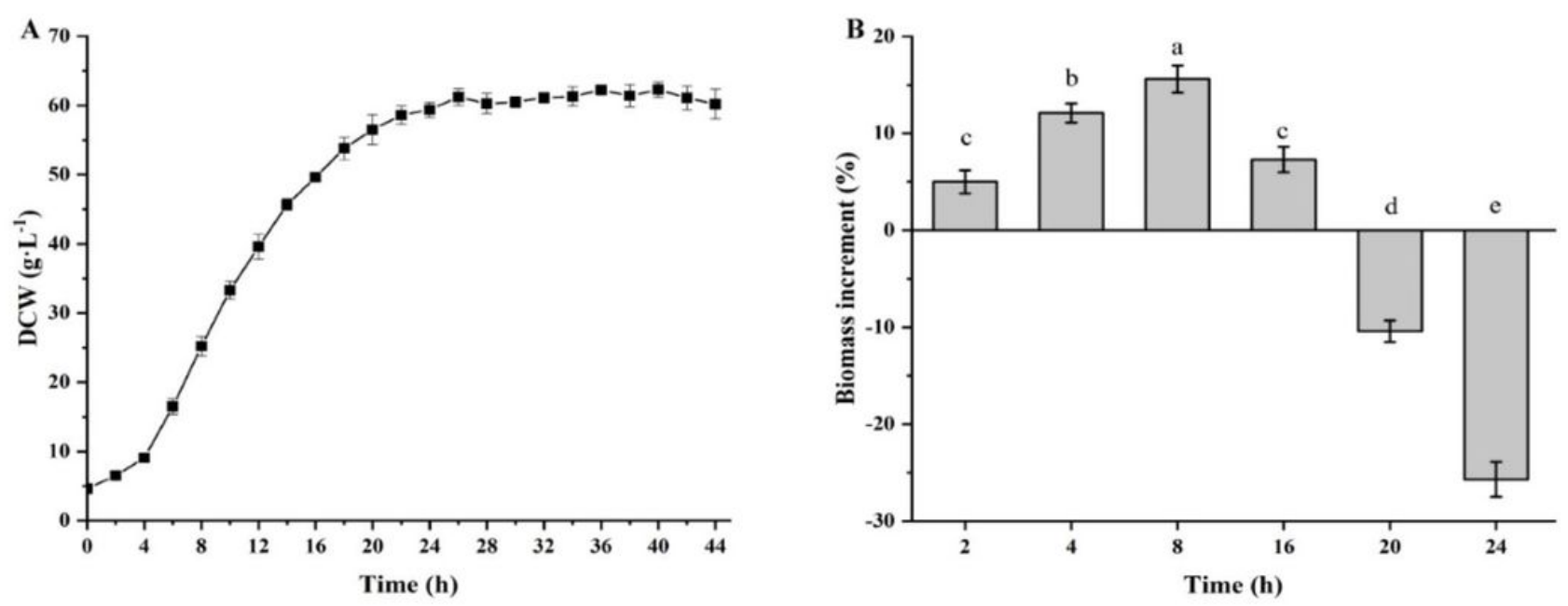

Figure 1

Effect of ultrasound on growth of C. glutamicum CP in different phase. A: The growth curve of C. glutamicum CP; B: biomass increment of C. glutamicum CP cultivated with ultrasound in different incubation time. Different letters indicate significant difference $(P<0.05)$. 
Fig. 2.
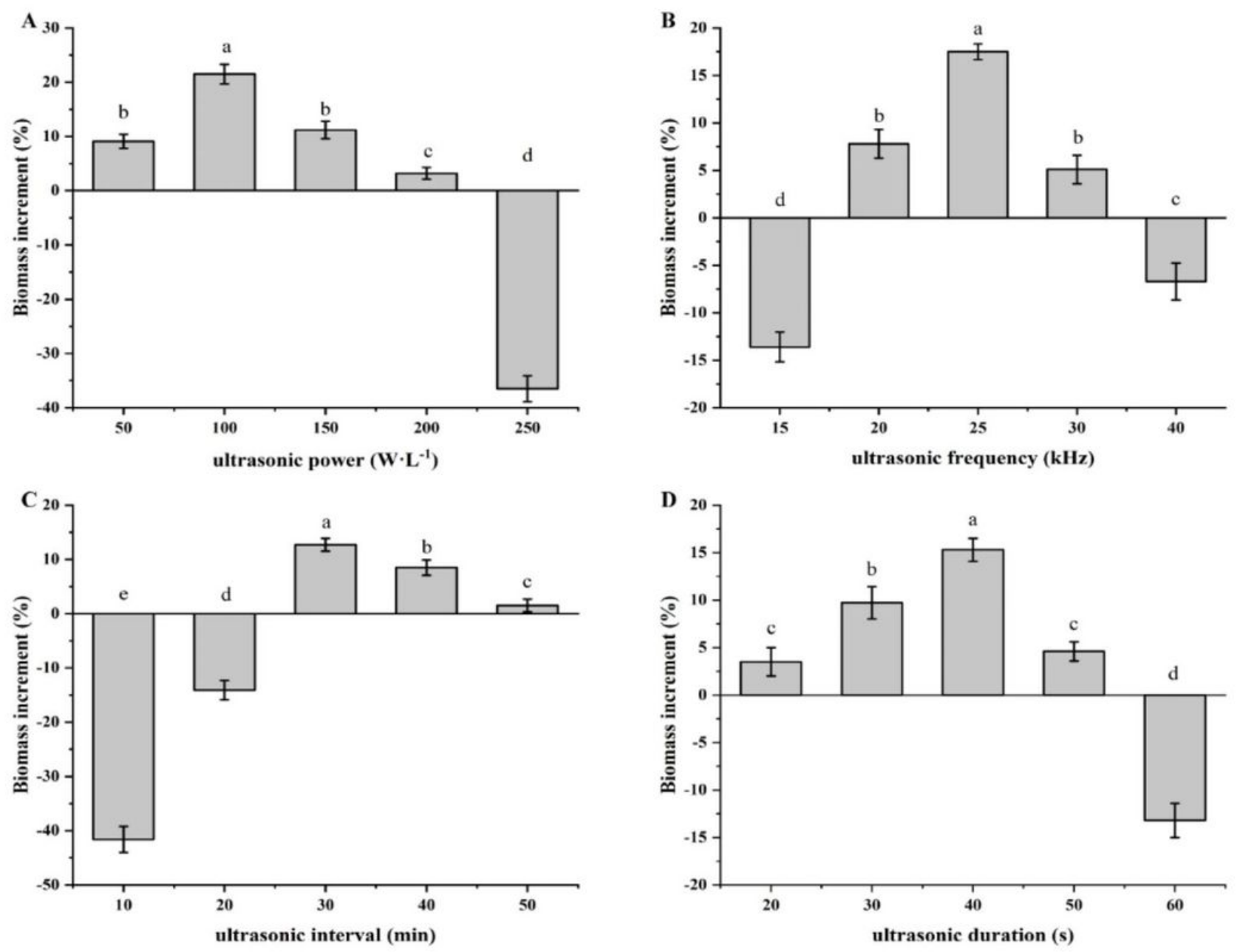

Figure 2

Effect of ultrasound parameters on growth of C. glutamicum CP. Biomass increment of C. glutamicum CP treated with the ultrasound under different powers $(A)$, different frequencies $(B)$, different intervals $(C)$, and different durations $(D)$. Letters indicate significant difference $(P<0.05)$. 
Fig. 3.
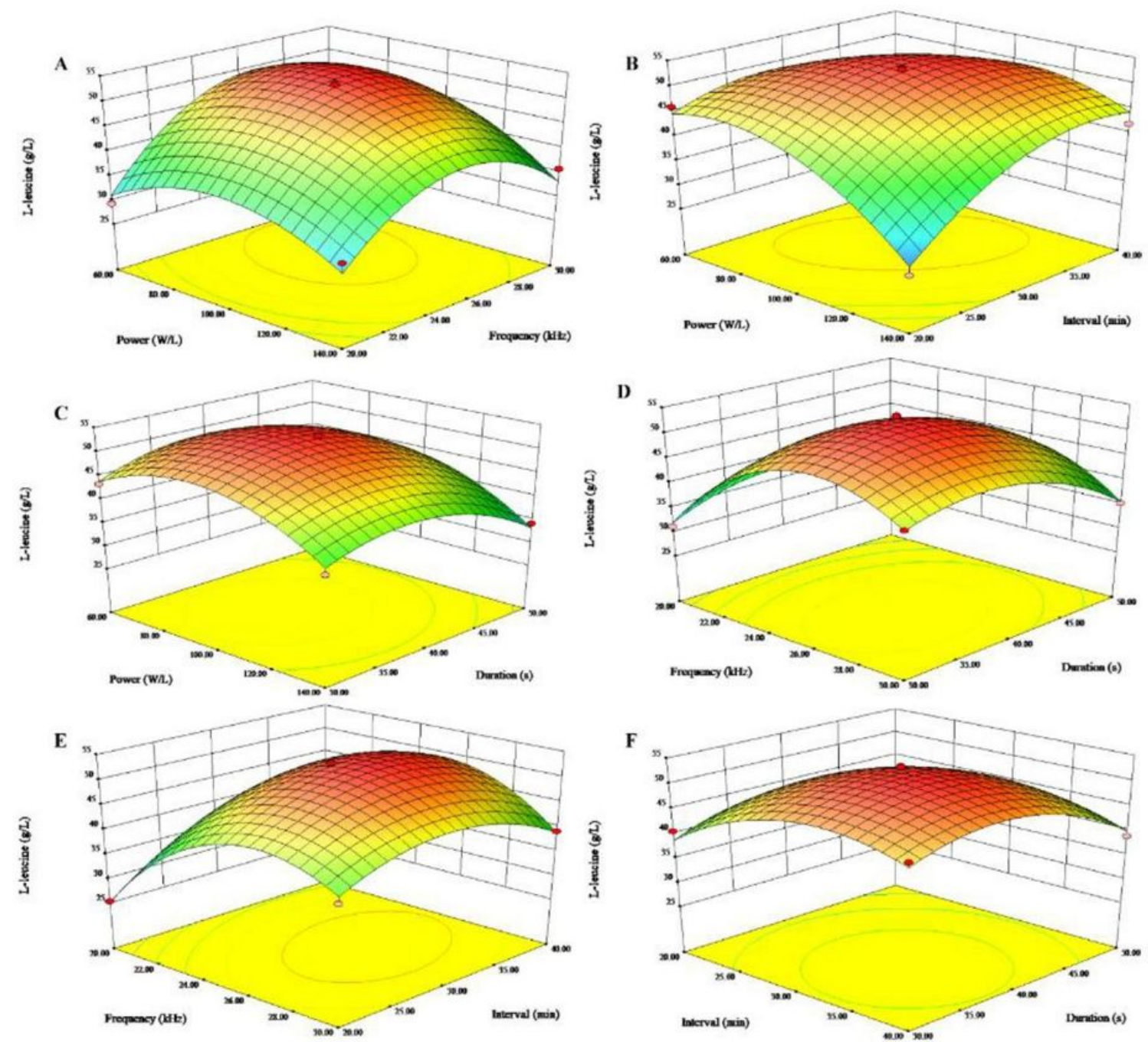

\section{Figure 3}

Response surface plot for interactions between four independent variables on the L-leucine production. The titer of L-leucine was observed as a response variable to the interaction of two independent variables. The remainder of parameters was at central points. Two variables were plotted against each other in each panel. 
Fig. 4.
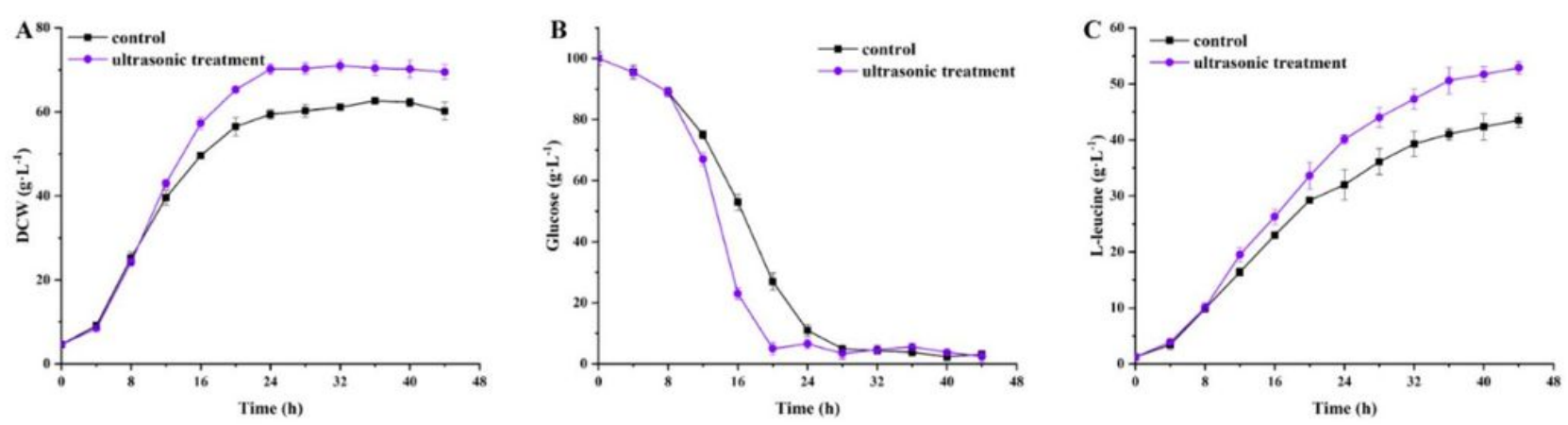

Figure 4

Time profiles of biomass (A), glucose (B), and L-leucine (C) concentrations in fed-batch fermentation by C. glutamicum $\mathrm{CP}$ in control experiments and ultrasonic experiments. All fermentation experiments were performed with three independent replicates $(n=3)$. 
Fig. 5.
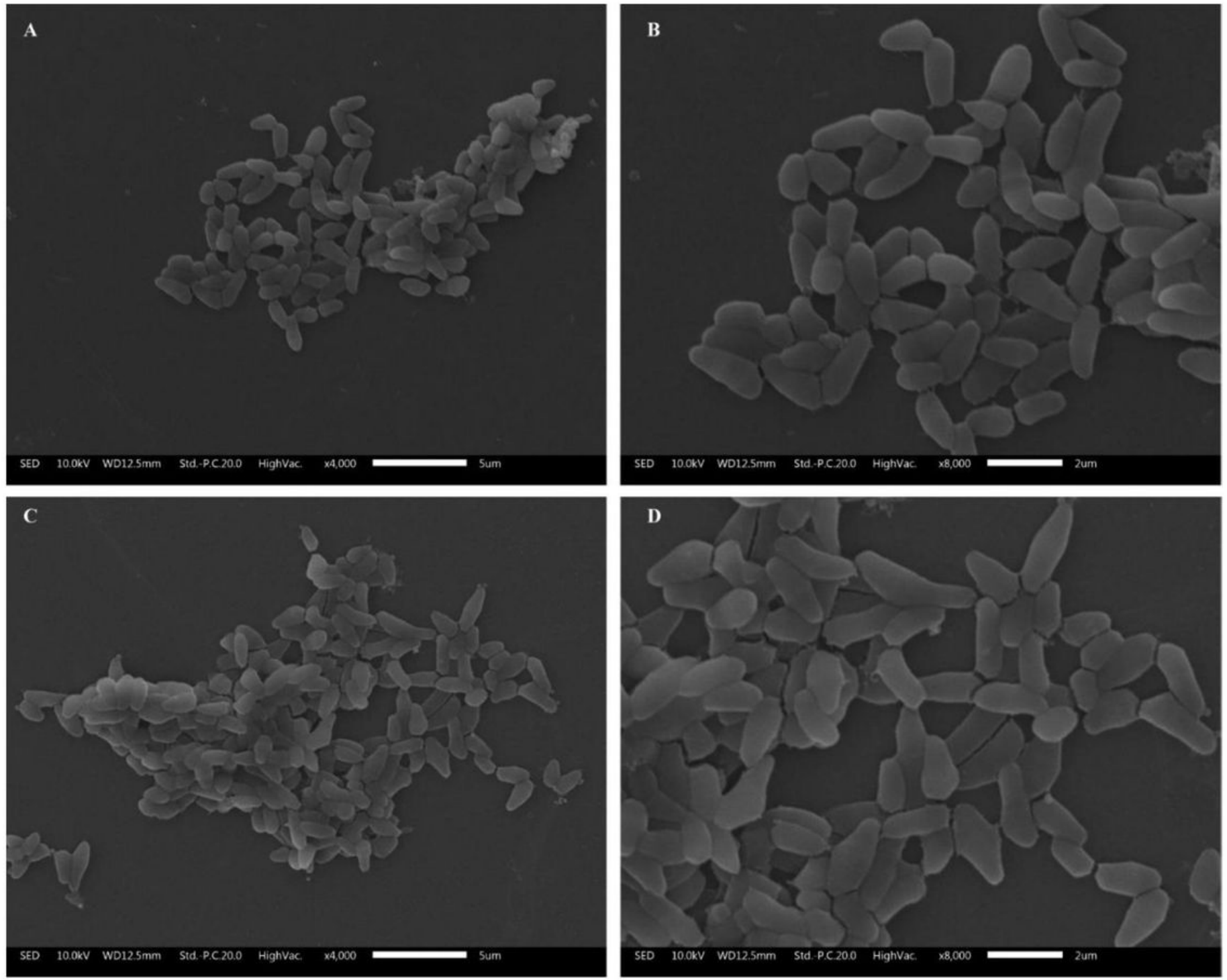

\section{Figure 5}

Electron microscopic observation of cell morphology of C. glutamicum CP with/without ultrasonic treatment. A-B: control cells; C-D: ultrasound treated cells. 
Fig. 6.
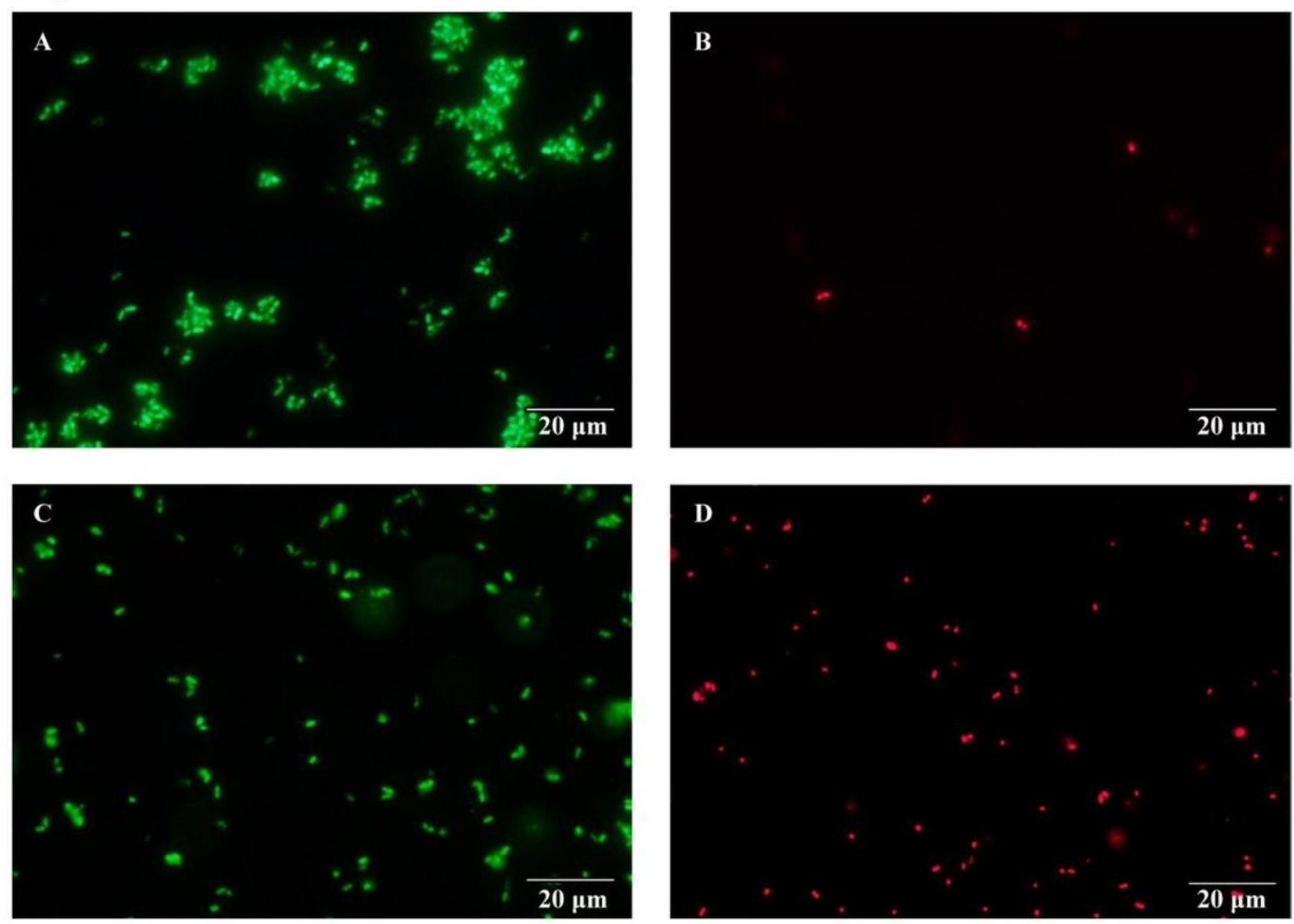

Figure 6

Fluorescence microscope images of C. glutamicum CP cells with/without ultrasonication. Greenfluorescent bacteria have an intact membrane; red fluorescent bacteria have a permeabilized membrane. A-B: control cells; C-D: ultrasound treated cells. 
Fig. 7.

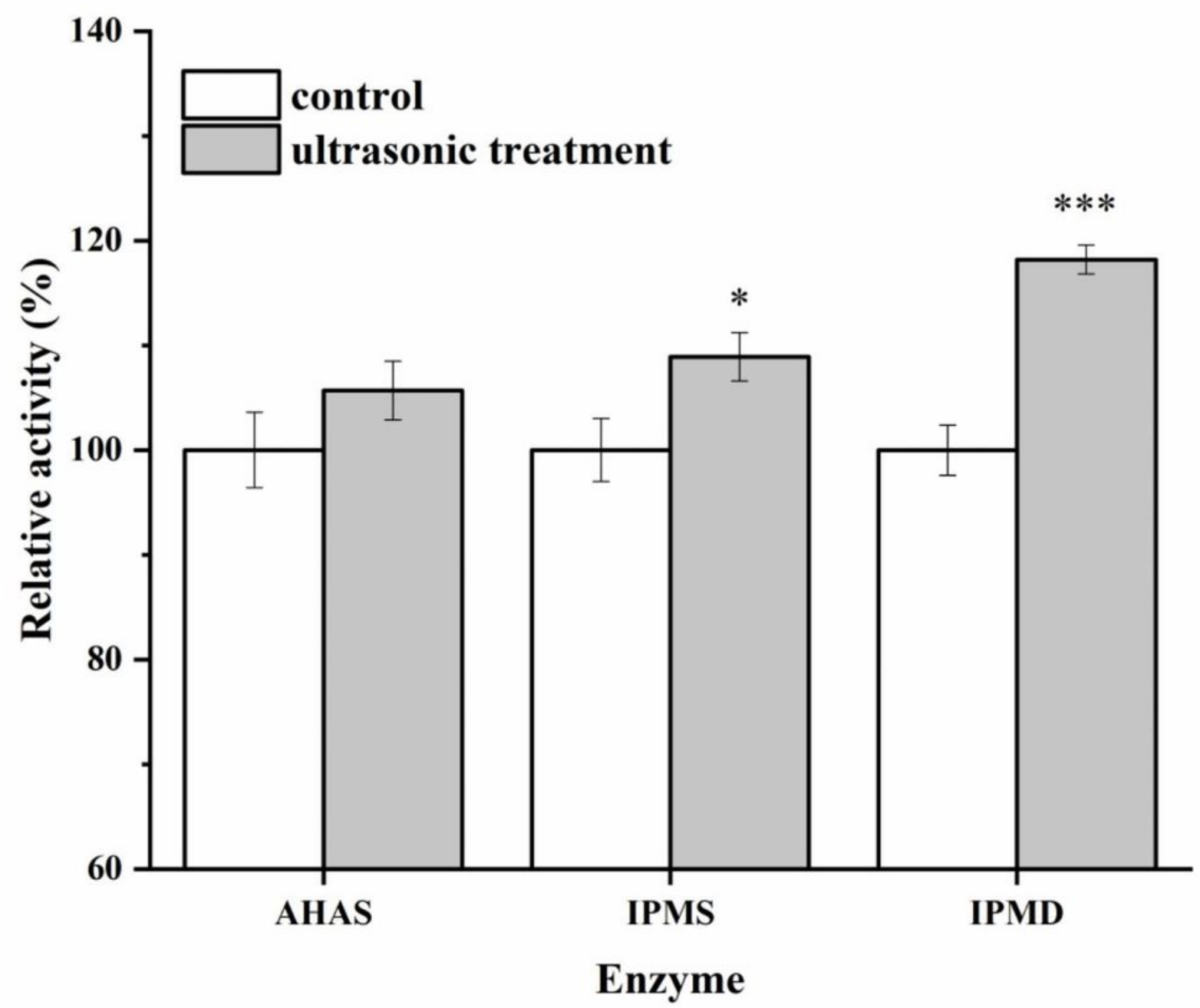

Figure 7

Relative activity of AHAS, IPMS, and IPMD in the stationary phase was determined. Data are presented as means \pm standard deviations from three independent experiments. ${ }^{*} \mathrm{P} \leq 0.05,{ }^{\star *} \mathrm{P} \leq 0.01,{ }^{\star \star *} \mathrm{P} \leq 0.001$.

\section{Supplementary Files}

This is a list of supplementary files associated with this preprint. Click to download.

- ZhangetalultrasoundAdditionalfile.pdf 